\title{
Evaluation of cost of
} treatment of drug-related events in a tertiary care public sector hospital in

\section{Northern India: a prospective study}

\section{Correspondence}

Professor Promila Pandhi, Department of Pharmacology, Postgraduate Institute of Medical Education and Research, Chandigarh-160 012, India.

Tel: +91-172-2755 241

Fax:+91-172-2743 451

E-mail:ppandhi17@hotmail.com

\section{Keywords}

drug related events, treatment cost, public sector hospital, India

\section{Received}

19 May 2008

Accepted

11 November 2008

Smita Pattanaik, Punit Dhamija, Samir Malhotra, Navneet Sharma ${ }^{1} \&$ Promila Pandhi

Departments of Pharmacology and 'Internal Medicine, PGIMER, Chandigarh, India

\section{WHAT IS ALREADY KNOWN ABOUT}

\section{THIS SUBJECT}

- Drug related events include ADRs, events due to patient or physician noncompliance, drug overdosage and drug interactions.

- Economic burden of management of drug related events are substantial and include both direct and indirect costs.

- Some data regarding cost of treatment of ADR exist from south and western India.

\section{WHAT THIS STUDY ADDS}

- An approximate cost of management of drug related events presenting to the emergency medical department in a tertiary care hospital over a period of 4 months.

- Compares the cost incurred in a public sector hospital to the projected cost of management of same events in a private sector hospital.

- Gives a rough estimate of economic burden on the health care system due to adverse drug events.

\section{AIMS}

Drug related events (DREs) contribute significantly to hospital admissions. These are largely preventable events and require optimum use of the therapeutic agents. The study was conducted to analyze the cost of treatment of DREs.

\section{PATIENTS \& METHODS}

All visits to medical emergency department of a tertiary care public sector hospital in northern India were recorded in a prospective, non-interventional manner over a period of 4 months. DREs were recognized and were followed up till their stay in the hospital. Data about the cost generating components of direct and indirect costs of treatment of DREs were collected. The projected cost of treatment of the same DREs in a private sector hospital was estimated and compared.

\section{RESULTS}

Out of 1833 admissions, 92(5.01\%) were due to DREs. Maximum cases were due to non compliance (66\%) followed by ADR $(28 \%)$ and drug overdose(6\%). The common DREs leading to ED visits were cerebrovascular accident(19.44\%), followed by accelerated hypertension(18.36\%) and diabetic ketoacidosis(14.04\%). Total cost of management of all the 92 DREs in our hospital was calculated to be INR17,37,339(€30,215). The direct cost was INR1,72,961(€3008) and the approximate indirect cost was INR15,64, 378(€27, 206). The projected cost of management of all the 92 DREs was estimated to be INR63,63,872( $€ 1,01,676)$ in a private sector hospital.

\section{CONCLUSION}

The study shows that ADEs leading to emergency department visits and hospitalizations constitute a significant economic burden. Training of the patients and the prescribers may lessen the economic burden on the patient as well as the health care system. 


\section{Introduction}

The aim of drug therapy is to achieve optimal therapeutic outcomes with minimal drug-related events (DREs) [1]. Unresolved or unrecognized DREs might manifest as drugrelated morbidity or mortality and may be reflected as therapeutic malfunction [2]. The incidence of drug-related admissions is reported to range from 0.2 to $21.7 \%$ [3]. Along with adverse drug reactions (ADRs), DREs include all kinds of medication errors that may be caused by patients, prescribers or dispensers. Most drug-related morbidity and mortality are events that are preventable through optimum use of the therapeutic agents [4].

The economic impact of DREs is immense on patients, healthcare providers, administrators and society. Cost estimates made in various studies are usually limited to the direct cost of managing drug-related morbidity and mortality [5-10]. A more complete estimation of the costs (from the socioeconomic perspective) associated with these health problems should also include indirect costs, i.e. expenditure on food, travel, stay and the economic burden due to lost productivity of patients as well as caregivers $[11,12]$. According to some authors the overall impact of cost of illness exceeds the direct cost and may be two to three times the estimated direct cost [13-15]. There is also a paucity of data regarding the economic impact of DREs in a public sector hospital from this part of India. The present study aimed to describe the overall economic impact of DREs leading to emergency department (ED) admissions in a tertiary care public sector hospital where services are provided at a subsidized price and to project the cost of similar admissions in a private sector hospital in an Indian set-up.

\section{Patients and methods}

All visits to the ED of our hospital were recorded over a period of 4 months (January to April 2005) in this prospective, non-interventional study. It is a 1500 -bed tertiary care hospital with a medical emergency having a multidisciplinary structure (internal medicine, cardiology, pulmonary medicine, nephrology, gastroenterology, endocrinology, neurology and intensive care, etc.) admitting patients aged $>12$ years. The resident doctors, nurses and pharmacists on duty were informed about the study objectives and were requested to report cases due to suspected DREs on a notification form. ADRs, patient noncompliance, physician noncompliance, drug interactions and drug overdosages were included as DREs. These cases were further reviewed by S.P. and P.D. to reassess the cause of the visit and categorize them as DREs leading to ED admissions and DREs leading to hospitalization (those requiring $>48 \mathrm{~h}$ of stay). All patients were also independently reviewed twice a day to determine if any cases had not been reported to us by the staff on duty.

All suspected DREs were discussed by S.P. and P.D. with the resident doctors and the consultant in charge of the ED within $24 \mathrm{~h}$ of admission. Cases for which $>80 \%$ agreement was obtained between data interpreters qualified as a drug-related visit for each case. DREs were analysed and details of demographic characteristics, socioeconomic status, diagnosis, type of DRE, clinical condition and severity, past medical history, drugs and other alternative therapy history, and personal history were collected. Patients were followed until the time of discharge from hospital and the following data were collected: duration of stay, details of drugs used during treatment, need for intravenous fluids, central line, oxygenation, catheterization, nasogastric tube aspiration/feeding, all investigations done, and interventions (if any). The causality assessment of ADRs was done by the Naranjo method [16]. DREs were also evaluated and assessed in terms of avoidability i.e. definitely avoidable, potentially avoidable and unavoidable.

\section{Definitions of drug-related events}

- ADR: Defined as any unintended reaction that occurs at doses used in humans for prophylaxis, diagnosis, therapy or modification of physiological processes as per the World Health Organization [17].

- Patient noncompliance: Patients and attendants were interviewed thoroughly and history was obtained in detail by asking questions such as 'how often do you ...? Do you ever take more or less of the prescribed amount for any specific reason...??'. Whenever required, family members were consulted for obtaining further information. Noncompliance and reasons for them were ascertained in a nonjudgmental way as described previously [18].

- Physician noncompliance: Inappropriate prescription consisting of inaccurate dosage or duration, or insufficient information regarding the prescribed drug was considered as physician noncompliance [19]. The patient's previous prescriptions were checked and corroborated with the patient's comprehension regarding the medication dosage, duration, etc., to discover patient or physician noncompliance.

- Drug overdose: History of all accidental and intentional overdoses was obtained from patients, relatives or accompanying attendants. This was confirmed by plasma concentration estimation whenever feasible.

- Drug interactions were considered to have occurred when the effects of one drug were modified by the presence of another drug [20].

Monetary value was assigned to the direct and indirect cost-generating components of therapy. Total economic 
burden was calculated by adding direct and indirect costs. Direct expenditures due to hospital admission were cost of the drugs and consumables, cost of hospital stay (which includes diet for the patient), investigations and interventions. Since this hospital is a public sector institution, services are available at subsidized rates and the patients are not charged for the stay, diet and investigations (haematology, biochemistry, $\mathrm{x}$-ray, ultrasonography, electrocardiogram, arterial blood gas analysis) during the first $48 \mathrm{~h}$ of admission. After $48 \mathrm{~h}$, the patients are charged as per hospital rates. Patients who were discharged within $48 \mathrm{~h}$ were considered ED visits. Patients whose treatment demands prolonged the stay in hospital $(>48 \mathrm{~h}$ ) were labelled as drug-related hospitalizations (DRHs) even if they could not be shifted to the inpatient wards due to non-availability of beds. Throughout the hospital stay cost of drugs and consumables was borne by the patient.

Indirect cost calculation included the cost of travel, food and stay for the attendants and loss of wages due to loss of productivity for both patient and attendants. Two attendants per patient were taken by default. For the cost of travel, one to and fro visit was included. A sensitivity analysis was conducted including the maximum, minimum and average expenditure per day per person for food, travel and wages. Expenditure on food was calculated for a minimum of two attendants per patient, taking an average meal, which ranges from INR30 (€0.52) to INR100 (€1.73) with an average of INR50 (€0.86). For calculation of travel expenses, autorickshaw fares for all local patients and the ordinary bus fare for all patients living further away were used as minimum. The use of ambulance services for travel was considered as maximum. Provision of free accommodation was available in the hospital premises when the recommendation had been forwarded by the treating physician. Loss of productivity was calculated on the basis of a minimum wages model in India, i.e. minimum of INR66 (€1.13) per day per head and maximum of INR330 (€5.8) $[21,22]$.

In India both public and private healthcare systems exist, catering to the needs of different strata of population. The projected cost of treatment of the same DREs was also estimated in a private sector hospital assuming that the same line of management was adopted in both settings. The fee structure for the private sector was based on the average of four private leading set-ups in the city.

\section{Results}

\section{Demography and incidence of DREs}

A total of 92 (5.01\%) admissions were considered to be due to DREs among 1833 patients screened, of which 80 (86\%) were definitely, seven (8\%) possibly and five (6\%) probably related to drugs. The commonest cause of DREs was non- compliance (66\%), followed by ADRs ( $28 \%$ ) and drug overdose (6\%). The demographic profile of patients having DREs is detailed in Table 1.

The three most common DREs leading to ED visits were cerebrovascular accident (CVA) (19.44\%), followed by accelerated hypertension (18.36\%) and diabetic ketoacidosis (14.04\%) (Figure 1). The majority of these were due to noncompliance. Nonsteroidal anti-inflammatory drugs (NSAIDs) were the most common (11/26) class of agents responsible for ADRs [upper gastrointestinal (GI) bleed $(9 / 26)$ and chronic renal failure (CRF) (2/26)]. Drug-induced (isoniazide, rifampicin, pyrazinamide, azathioprine) hepatitis (3/26), warfarin-induced bleeding $(3 / 26)$ and rash (rifampicin, tazobactam) (2/26) were other common ADRs. Visits due to drug overdose were fewer in number compared with other ADRs (4\%). The most common form of drug overdose was with phenytoin, leading to vertigo, nystagmus and arrhythmia. Other DREs related to drug overdose were tricyclic antidepressants and diazepam.

Of the 92 DREs reported, 51 (55\%) were definitely avoidable, $13(15 \%)$ potentially avoidable and the remaining 28 (30\%) unavoidable. Drug overdose during attempted suicides and known side-effects of drugs were considered unavoidable. There were two deaths that could be attributed to drugs (neutropenic sepsis in a renal transplant patient and upper Gl bleed) during the observation period of the study.

\section{DREs and hospital stay}

All 92 DREs led to a total of 266 days of hospital stay including 150 inpatient days. The median number of days of stay in the hospital (including days of ED stay and inpatient stay) was 3 days with a maximum of 6 days and minimum of 1 day. There were 45 (49\%) DRHs out of the total 92 DREs

\section{Table 1}

Demographic profile of patients with drug-related events

\begin{tabular}{|c|c|c|c|}
\hline Age, years; $n(\%)$ & $\begin{array}{l}\text { Noncompliance } \\
(n=61)\end{array}$ & ADR $(n=26)$ & $\begin{array}{l}\text { Drug } \\
\text { overdose }\end{array}$ \\
\hline$<20$ & $4(6.5)$ & $1(4)$ & $1(20)$ \\
\hline $21-40$ & $11(19)$ & $13(50)$ & $4(80)$ \\
\hline $41-60$ & $29(47)$ & $9(34)$ & 0 \\
\hline $61-80$ & $15(24.5)$ & $3(12)$ & 0 \\
\hline$>80$ & $2(3)$ & 0 & 0 \\
\hline Gender; M/F (\%) & $35 / 26$ & $15 / 11(n=26)$ & $3 / 2(n=5)$ \\
\hline \multicolumn{4}{|c|}{ Monthly family income; INR (€) } \\
\hline$<5000(869)$ & 19 & 8 & 1 \\
\hline 5000-10 000 (869-1739) & 21 & 9 & 3 \\
\hline$>10000$ (1739) & 11 & 9 & 1 \\
\hline \multicolumn{4}{|l|}{ Education } \\
\hline$<$ Primary & 27 & 5 & 1 \\
\hline $\begin{array}{l}\text { Matriculation/Higher } \\
\text { Secondary }\end{array}$ & 30 & 10 & 3 \\
\hline Graduation and above & 4 & 5 & 1 \\
\hline
\end{tabular}


leading to ED visits. Medication noncompliance was responsible for the longest duration of stay in hospital, contributing to $69 \%$ of total days spent in hospital due to DREs. The maximum stay was 8 days in a case of diabetic ketoacidosis (DKA) and the minimum 1 day in accelerated hypertension, disulfiram reaction, drug-induced dystonia, metoprolol-induced complete heart block and diazepam overdose. Complications of diabetes such as DKA were the most important cause for extended hospital stay, followed by CVA and upper Gl bleed.

\section{Economic impact of DREs}

The total cost of management of all the 92 DREs in our hospital was calculated to be INR1737 339 (€30 215). From the patients' perspective, the direct cost was INR172 961 (€3008) and the approximate indirect cost was INR1564 378 (€27 206). The major share of the direct cost was due to the drugs (54\%) used for treatment. Direct cost of management accounted for $10 \%$ of total cost of management when the cost of services provided by the hospital to the patient in the first $48 \mathrm{~h}$ of admission was not included. There was a $20 \%$ increase in the direct cost when we calculated these charges.

Medication noncompliance was the single most important contributor to this cost ( $85 \%$ of the total cost), followed by ADRs ( $13 \%$ of the total cost). Management of drug overdose leading to hospitalization incurred the least expenditure (Table 2).

In terms of total cost, DKA followed by CVA, accelerated hypertension and upper Gl bleed contributed most to the total expenditure of management of DREs. DKA itself constituted 33\% (for 13 cases) of the cost of management of

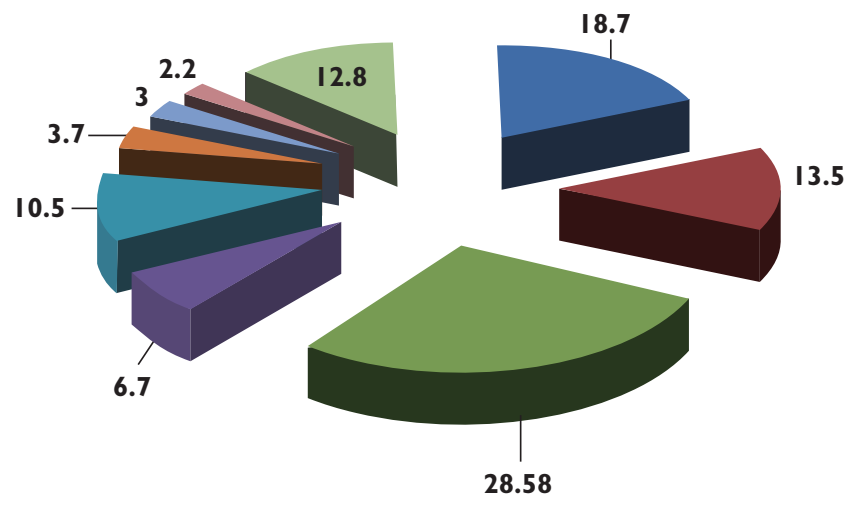

Figure 2

Days of hospital stay due to drug-related events (DREs) (in percentage). CVA ( $\square$ );HTN ( $\square$ );DKA ( $\square$ ); Seizures ( $\square$ ); UGI Bleed ( $\square$ ); NSAID CRF ( $\square$ );

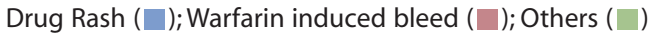

all 92 DREs. Total cost of management per case as well as economic loss due to loss of productivity was highest in DKA (Figure 3). In terms of direct cost per case, immunosuppressant-induced neutropenia leading to sepsis in a renal transplant patient was the most expensive DRE, followed by NSAID-induced CRF (Figure 2).

Sensitivity analysis was conducted considering the variability in the components of the indirect costs. The minimum total cost of management of all DREs was INR983 230 (€17 099) and the maximum was INR5551 101 (€96373). The projected cost of management of all 92 DREs was estimated to be INR6363 862 (€101676) in a private set-up.

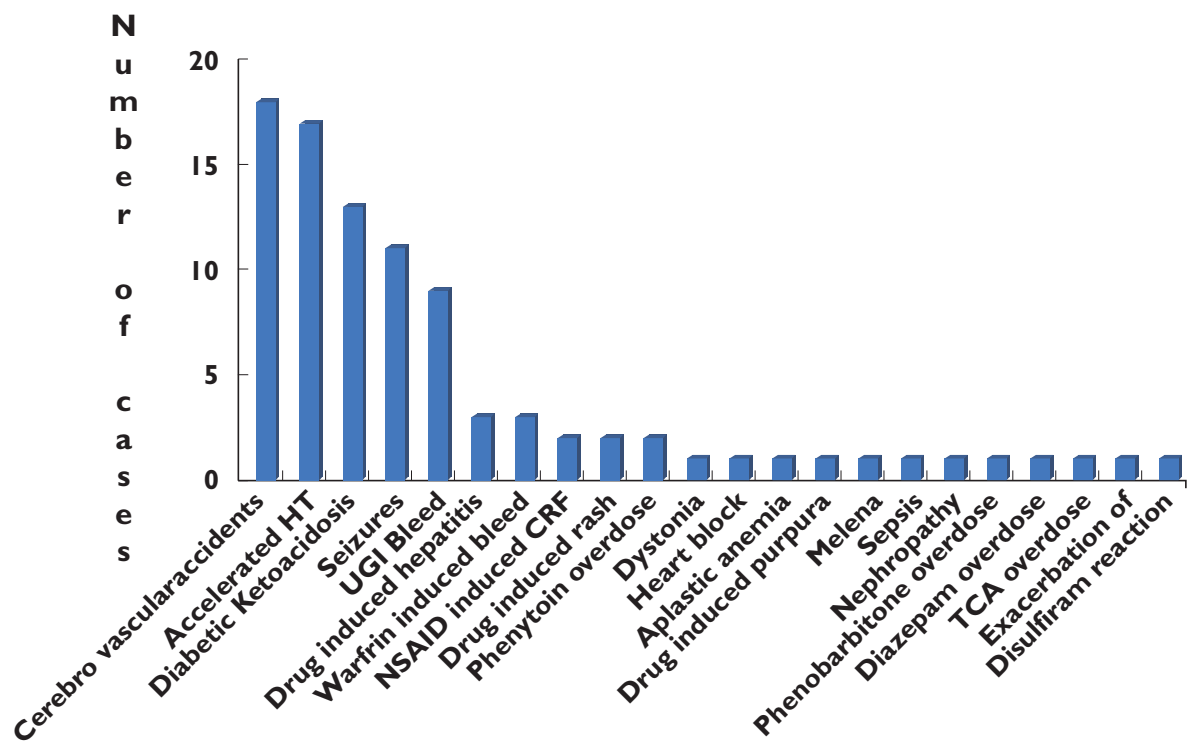

\section{Figure 1}

Causes of drug-related events 
Table 2

Cost-generating components of the drug-related events

\begin{tabular}{|c|c|c|c|}
\hline Direct cost: components & Noncompliance; INR (€) & Adverse drug reaction; INR (€) & Drug overdose; INR (€) \\
\hline Drugs & $59303(1031)$ & $32535(566)$ & $483(8)$ \\
\hline Investigations and interventions & $25030(435)$ & 10019 (174) & $475(8)$ \\
\hline Consumables & $19810(344)$ & 11406 (198) & $575(10)$ \\
\hline \multicolumn{4}{|l|}{ Indirect cost: components } \\
\hline Loss of wages & $1076724(18726)$ & 133848 (2 328) & $4752(83)$ \\
\hline Total cost & $1215324(21$ 136) & $319500(5556)$ & $29554(514)$ \\
\hline
\end{tabular}

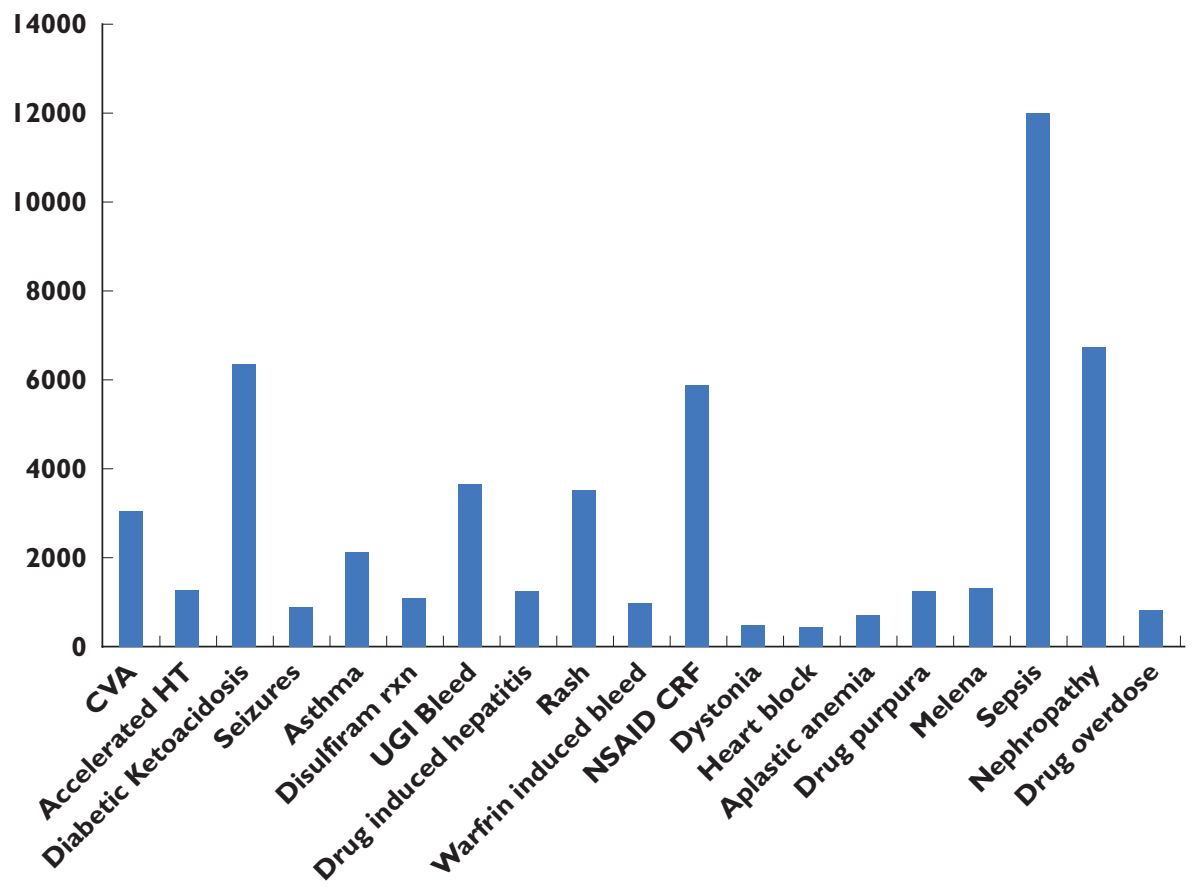

\section{Figure 3}

Total cost of management of drug-related events (DREs) per case

\section{Discussion}

Although a number of studies have evaluated the pharmacoeconomic impact of DREs in the developed world [5-9, 11-15], limited data are available from developing countries $[9,21,22]$. Moreover, most of them have evaluated the burden of ADRs only, not DREs. Our study has shown DREs to be important contributors to the economic burden on the healthcare system in a developing country. Compared with our previous study [23], done in 2001, the percentage of DREs has remained similar (about 5\%), although we did not calculate the cost of DREs.

In our study, patient noncompliance caused the most ED visits (66\%) and accounted for $85 \%$ of all expenditure on DREs. Patients suffering from chronic diseases such as hypertension and diabetes were found to be least compliant. In a previous study in an elderly population, the most common reason for noncompliance was found to be forgetfulness, followed by ADRs [18]. The most common reasons for noncompliance in our study were inadequate knowledge about the disease, poor comprehension of the need for regular medication followed by forgetfulness. We found that, in many cases, noncompliance was due to the misconception that once blood pressure, blood sugar, seizures, etc. are under control there is no need to continue the medications. Another reason could be inappropriate communication between the patient and attending physician. A frequent source of noncompliance seen in our 
population (observed in our earlier study also) was discontinuation of modern medicines and switching to traditional medicines of doubtful efficacy (generally prescribed by ill-qualified practitioners) leading to complications. Such switching in most cases was due to the belief that modern medications cause a lot of side-effects and natural remedies, homeopathy, herbal preparations, etc. do not.

As seen in earlier studies $[9,16]$, we noticed that nearly $70 \%$ of the DREs were possibly avoidable. The role of explicit instructions to patients by physicians cannot be overemphasized in reducing the economic burden of DREs.

The average total expenditure was around $€ 328$ per case, with a maximum of $€ 740$ and minimum of $€ 15$. In previous studies from India, the cost of management of one ADR in a public sector hospital were found to be $€ 6-100[8,23]$. However, these did not include indirect costs. A salient finding of our study was that the indirect cost of management of DREs was several-fold higher than the direct cost. This occurred even though we followed DREs only until the end of the period of hospitalization, whereas some costs like loss of wages might have continued beyond that.

The direct cost of treatment further increased by $20 \%$ if expenditure (investigations, stay, food) during the first $48 \mathrm{~h}$ was included. However, this being a public sector hospital, this cost is borne by the healthcare system. The projected cost of management of the same DREs in a private sector hospital was calculated to be nearly four times that of a public sector hospital. Of all the contributors to the direct cost, the major cost was drug treatment $(54 \%)$, followed by investigation and interventions, consumables (Table 3 ) and hospital stay charges. However, the cost of drugs and consumables would be the same when the DREs were managed in a private sector hospital. Interestingly, the other components of the direct cost, i.e. cost of hospital stay and cost of investigations and interventions, were 8-10 times in the public and private sectors. These two components of the direct cost were the main contributors to the difference in cost of management of the DREs in both set-ups. Additional components of direct cost such as consultation fees, night visit charges, nursing charges and patients' diet charges were vastly different in public and private sector hospitals. Healthcare facilities in public sector hospitals in India are highly subsidized.

In conclusion, this study has provided a fair estimate of the expenditure to the patient and the healthcare system due to the burden of DREs. Patient education with respect to the need of continuing treatment could be a single step to prevent many of these events.

\section{Competing interests}

None declared.

\section{Table 3}

Cost of consumables

\begin{tabular}{|c|c|}
\hline Items & Cost INR (€) \\
\hline I.v. fluids & $20(0.34)$ \\
\hline 5\% Dextrose & $20(0.34)$ \\
\hline $5 \%$ Dextrose normal saline & $40(0.7)$ \\
\hline $10 \%$ Dextrose & $40(0.7)$ \\
\hline \multicolumn{2}{|l|}{ Ringer lactate } \\
\hline I.v. transfusion set & $15(0.25)$ \\
\hline Blood transfusion set & $20(0.34)$ \\
\hline Central line & $1300(22.4)$ \\
\hline Nasogastric tube & $10(0.2)$ \\
\hline I.v. canula (veinflon) & $35(0.6)$ \\
\hline Syringes $50 \mathrm{ml}$ & $25(0.43)$ \\
\hline With needle $20 \mathrm{ml}$ & $10(0.2)$ \\
\hline $10 \mathrm{ml}$ & $5(0.1)$ \\
\hline $5 \mathrm{ml}$ & $3(0.05)$ \\
\hline $2 \mathrm{ml}$ & $3(0.05)$ \\
\hline Urinary catheter (Foleys) & $160(2.75)$ \\
\hline Glucometer strips & $25(0.5)$ \\
\hline Gloves & $25(0.5)$ \\
\hline Urine culture container & $10(0.2)$ \\
\hline
\end{tabular}

The values are averaged over three available brands in Indian (includes lower, higher and medium range).

\section{REFERENCES}

1 Helper CD, Strand LM. Opportunities and responsibilities in pharmaceutical care. Am J Hosp Pharm 1990; 47: 533-43.

2 Strand LM, Morley PC, Cipolle RJ, Ramsay R, Lasman GD. Drug related problems: their structure and function. Drug Intell Clin Pharm 1990; 24: 1093-7.

3 Bates DW, Miller EB, Cullen DJ, Burdick L, Williams L, Laird N, Petersen LA, Small S, Sweitzer B, Vliet MV, Leape LL. Patient risk factors for adverse drug events in hospitalized patients. Arch Intern Med 1999; 159: 2553-60.

4 Bates DW, Spell N, Cullen DJ, Burdick E, Laird N. The cost of adverse drug events in hospitalized patients. J Am Med Assoc 1997; 277: 307-11.

5 Ayani I, Aguirre C, Gutiérrez G, Madariaga A, Rodríguez-Sasiaín JM, Martínez-Bengoechea MJ. A cost-analysis of suspected adverse drug reactions in a hospital emergency ward. Pharmacoepidemiol Drug Saf 1999; 8: 529-34.

6 White TJ, Arakelian A, Rho JP. Counting cost of drug related adverse events. Pharmacoeconomics 1999; 15: 445-58.

7 Gautier S, Bachelet H, Bordet R, Caron J. The cost of adverse drug reactions. Expert Opin Pharmacother 2003; 4: 319-26.

8 Dartnell JG, Anderson RP, Chohan V. Hospitalisation for adverse events related to drug therapy: incidence, avoidability and costs. Med J Aust 1996; 164: 659-62.

9 Patel KJ, Kedia MS, Bajpai D, Mehta SS, Kshirsagar NA, Gogtay NJ. Evaluation of the prevalence and economic burden of adverse drug reactions presenting to the medical 
emergency department of a tertiary referral centre: a prospective study. BMC Clin Pharmacol 2007; 7: 8.

10 Goettler M, Schneeweiss S, Hasford J. Adverse drug reaction monitoring - cost and benefit considerations. Part II: cost and preventability of adverse drug reactions leading to hospital admission. Pharmacoepidemiol Drug Saf 1997; 6 (Suppl. 3): S79-90.

11 Johnson JA, Bootman JL. Drug related morbidity and mortality: a cost of illness model. Arch Intern Med 1995; 155: 1949-56.

12 Sullivan JW. A pharmaceutical manufacturer's perspective on reporting adverse drug experiences. Am J Hosp Pharm 1990; 47: 1342-5.

13 Beringer PM, Wong-Beringer A, Rho JP. Economic aspects of antibacterial adverse effects. Pharmacoeconomics 1998; 13 : 35-49.

14 Lundkvist J, Jönsson B. Pharmacoeconomics of adverse drug reactions. Fundam Clin Pharmacol 2004; 18: 275-80.

15 World Health Organization. Intensive Drug Monitoring: the Role of National Centers. WHO technical report series No 498. Geneva: World Health Organization, 1972.
16 Col N, Fanale JE, Kronholm P. The role of medication non-compliance and adverse drug reactions in hospitalizations of the elderly. Arch Intern Med 1990; 150: 841-5.

17 Laurence DR, Bennett PN, Brown MJ. Clinical Pharmacology, 8th edn. London: Churchill Livingstone, 1997.

18 Stockly IH. Drug Ineractions, 3rd edn. Oxford: Blackwell Scientific Publications, 1994.

19 Available at http://www.economagic.com/em-cgi/data.exe/ fedstl/exinus (last accessed 15 January 2008).

20 Debroy B. What is India's per capita income? Oct 15, 2005. Available at http://in.rediff.com/money/2005/oct/ 13income.htm (last accessed 15 January 2008).

21 Ramesh M, Pandit J, Parthasarathi G. Adverse drug reactions in a south Indian hospital - their severity and cost involved. Pharmacoepidemiol Drug Saf 2003; 12: 687-92.

22 Arulmani R, Rajendran SD, Suresh B. Adverse drug reaction monitoring in a secondary care hospital in South India. Br J Clin Pharmacol 2007; 65: 210-6.

23 Malhotra S, Jain S, Pandhi P. Drug-related visits to the medical emergency department: a prospective study from India. Int J Clin Pharmacol Ther 2001; 39: 12-8. 